\title{
Inhibitory effect of plant essential oils on Malassezia strains from Iranian dermatitis patients
}

\author{
Ali Reza Naeini ${ }^{1}$, Mehdi Nazeri ${ }^{2}$, Hojjatollah Shokri ${ }^{3 *}$ \\ ${ }^{1}$ Member of the Faculty of Medicine and Medicinal Plants Research Center, Shahed University, Tehran, Iran \\ ${ }^{2}$ Department of Medical Parasitology and Mycology, Faculty of Medicine, Kashan University of Medical Sciences, Kashan, Iran \\ ${ }^{3}$ Department of Pathobiology, Faculty of Veterinary Medicine, Amol University of Special Modern Technologies, Amol, Iran
}

\section{A R T I C L E I N F O}

Article Type:

Original Article

Article History:

Received: 3 September 2017

Accepted: 3 December 2017

\section{Keywords:}

Anti-Malassezia activity

Medicinal plants

Cuminum cyminum

Lavandula stoechas

Ketoconazole

\begin{abstract}
A B S T R A C T
Introduction: The genus Malassezia is an important skin resident of human. The present study aimed to analyze in vitro activity of the essential oils of Lavandula stoechas, Cuminum cyminum and Artemisia sieberi against clinical strains of Malassezia species.

Methods: A total of 47 Malassezia strains, including Malassezia furfur, Malassezia globosa and Malassezia obtuse, were used in this study. A disk diffusion technique was selected for testing the susceptibility of Malassezia strains to the essential oils.

Results: All the essential oils showed in vitro activity against Malassezia strains, with M. furfur and M. obtusa being the highest and lowest susceptible of the strains, respectively. The highest antifungal activity was associated with the essential oil of C. cyminum (mean \pm SD: $50.0 \pm 0.0 \mathrm{~mm}$ ), followed by L. stoechas (mean \pm SD: $46.8 \pm 3.1 \mathrm{~mm}$ ) and A. sieberi (mean \pm SD: $36.9 \pm 5.7 \mathrm{~mm}$ ). The inhibition zone ranges were 12.5 to $15.6 \mathrm{~mm}$ (mean \pm SD: $14.4 \pm 1.6 \mathrm{~mm}$ ) for ketoconazole and 11.6 to $13.3 \mathrm{~mm}$ (mean \pm SD: $12.4 \pm 0.9 \mathrm{~mm}$ ) for fluconazole. Although all the antifungal drugs were found to possess good antifungal activities against Malassezia strains, their effects were lower than the activities shown by the essential oils tested $(P<0.05)$.

Conclusion: These results indicated that the essential oils tested, especially the one from C. cyminum, inhibited the growth of clinical strains of Malassezia, implying its potential use in the treatment of Malassezia infections. This indicates that this plant may be useful in preparation of new drugs.
\end{abstract}

Implication for health policy/practice/research/medical education:

The essential oils of C. cyminum, L. stoechas and A. sieberi showed promising antifungal effects against Malassezia strains from patients with Malassezia dermatitis as important fungal pathogens. Hence, these essential oils, especially C. cyminum, could be used to develop an effective therapy against skin infections caused by Malassezia strains.

Please cite this paper as: Naeini AR, Nazeri M, Shokri H. Inhibitory effect of plant essential oils on Malassezia strains from Iranian dermatitis patients . J Herbmed Pharmacol. 2018;7(1):18-21. doi: 10.15171/jhp.2018.04.

\section{Introduction}

Members of Malassezia genus are the normal mycoflora on human cutaneous surfaces. They colonize the regions containing sebaceous glands like the head, neck and shoulders of humans (1). The genus of Malassezia has been divided into 14 various species based on the last taxonomic revision (2). Malassezia species are associated with a wide spectrum of clinical signs, such as Tinea versicolor, Folliculitis and Seborrheic dermatitis. It also causes systemic infections in immune-compromised patients (3). The conditions that cause Malassezia-related infections in humans are not fully understood but researchers have been able to determine the role of different factors including genetic and environmental factors, imbalance in skin normal biota, immune suppression and profuse sweating as agents for these infections (4).

The antifungal therapies with different drugs, especially azoles, are generally successful in controlling the yeast overgrowth, but treatment failure and rapid recurrences are common (5). Therefore, considering the limitations of currently available antifungal drugs, the search for natural effective drugs is justified.

Iranian plants, such as Lavandula stoechas) (known as Ostokhodos), C. cyminum (known as Ziree) and 
Artemisia sieberi (known as Dermane) have been used for centuries as herbal remedies by local or regional subjects $(6,7)$. Several reports indicated the inhibitory activities of essential oils of the above-mentioned plants against different fungal agents (8-10). This study evaluated the antifungal activity of $L$. stoechas, C. cyminum and $A$. sieberi essential oils against clinical strains of Malassezia from the skin of patients with Malassezia dermatitis.

\section{Materials and Methods}

\section{Malassezia identification}

Forty-seven clinical strains of Malassezia were included in this study. Strains of Malassezia were maintained on modified Dixon's agar (Difco, USA) containing $6 \mathrm{~g}$ peptone (Oxoid), $20 \mathrm{~g}$ ox bile (Oxoid), $36 \mathrm{~g}$ malt extract, $2 \mathrm{~mL}$ glycerol, $2 \mathrm{~mL}$ oreic acid and $12 \mathrm{~g}$ agar at $32^{\circ} \mathrm{C}$ for 7 days. The yeasts were identified based on microscopic morphology and physiological characteristics, including catalase reaction, Tween assimilation and esculin hydrolysis tests to distinguish among different Malassezia strains (11).

\section{Medicinal plants}

Three herbal genera, such as L. stoechas, C. cyminum and A. sieberi, were sleeted according to the Iranian traditional practices (Table 1). Botanical identification was carried out in the herbal medicine laboratory of Shahed University (Tehran, Iran).

\section{Disc-based testing}

Anti-Malassezia susceptibility testing by disc diffusion method was carried out based on the Clinical \& Laboratory Standards Institute (CLSI) guidelines (CLSI document M44-A2) and manufacturer's instructions (12). For disc testing, the modified Dixon's medium was used. The yeast colonies were mixed in $5 \mathrm{~mL}$ of sterile distilled water, and the turbidity was adjusted to yield $1 \times 10^{5}-1 \times 10^{6}$ cells $/ \mathrm{mL}$ (0.5 McFarland standard). Yeast cells were inoculated on the agar surface using a sterile cotton swab. Subsequently, paper discs moistened with undiluted essential oils were placed on the media. In addition, discs containing ketoconazole and fluconazole $(10 \mu \mathrm{g} / \mathrm{disc}$, Master group, England) were placed on the media. The media were incubated at $32^{\circ} \mathrm{C}$ for 4 days and the zones of inhibition around the discs were measured. Disc moistened with sterile distilled water was considered as control. Each treatment was replicated twice for each sample.

Statistical analysis

Two-tailed paired student's $t$ test was used for analyzing the anti-Malassezia activities of the essential oils. A $P$ value less than 0.05 was considered to be statistically significant.

\section{Results}

As shown in Table 2, all three essential oils had inhibitory activities against different Malassezia strains at first screening. The zone diameters of yeast growth inhibition of the essential oils were between 15 and $50 \mathrm{~mm}$. The highest antifungal activity was associated with the essential oil of C. cyminum (mean \pm SD: $50.0 \pm 0.0 \mathrm{~mm}$ ), followed by L. stoechas (mean \pm SD: $46.8 \pm 3.1 \mathrm{~mm}$ ) and A. sieberi (mean \pm SD: $36.9 \pm 5.7 \mathrm{~mm}$ ). There were no significant differences among the essential oils tested against clinical strains of Malassezia $(P>0.05)$. A. sieberi essential oil indicated lower anti-Malassezia activity than the others. For 46 clinical strains of Malassezia, the inhibition zone ranges were 12.5-15.6 mm (mean \pm SD: $14.4 \pm 1.6 \mathrm{~mm}$ ) for ketoconazole and 11.6-13.3 mm (mean \pm SD: $12.4 \pm 0.9$ $\mathrm{mm}$ ) for fluconazole. There was no significant difference between the standard antifungal drugs tested against Malassezia strains $(P>0.05)$.

\section{Discussion}

The antimicrobial activity of herbal plants has attracted much interest from scientists as a result of the growing problem of drug resistance among pathogenic fungi. For this reason, the current study was done for investigating the importance of herbal essential oils as anti-Malassezia agents. The results showed that the essential oils of L. stoechas, C. cyminum and A. sieberi had inhibitory activities against different Malassezia strains. The zone diameters of growth inhibition of the essential oils ranged from 15 to $50 \mathrm{~mm}$. The highest antifungal activity was associated with the essential oil of C. cyminum (mean \pm SD: $50.0 \pm 0.0 \mathrm{~mm}$ ), followed by L. stoechas (mean \pm SD: $46.8 \pm 3.1 \mathrm{~mm}$ ) and A. sieberi (mean \pm SD: $36.9 \pm 5.7$ $\mathrm{mm})$. There were no significant differences among the essential oils tested against Malassezia strains. Several publications on antifungal activity of the essential oils against Malassezia species were reported in the literature $(4,13,14)$. Our results are consistent with those found by Naeini et al (15) who reported C. cyminum being the most active essential oil with a mean inhibition zone of $48.3 \mathrm{~mm}$ against different Malassezia strains. Vijayakumar et al (16) observed inhibition zones of 5.3-30 mm by different herbal plants against Malassezia strains. The inhibitory and fungicidal activities of C. cyminum are related to the mark vacuolation in the cytoplasm, isolation of fibrillar layer of cell wall, disruption of plasma and nuclear membranes and a large swelling in the mitochondrial matrix (17).

Table 1. Some characteristics of the tested plants

\begin{tabular}{lccccc}
\hline Scientific name & Voucher No. & Family & Local name & Medicinal use & Major components \\
\hline Lavandula stoechas & 101 & Labiatae & Ostokhodos & Antispasmodic, carminative, wound healing & Fenchone, camphor, cineole \\
Cuminum cyminum & 1172 & Apiaceae & Ziree & Carminative, antidiarrhoeaic, antispasmodic & $\alpha$-Pinene, cineole, linalool \\
Artemisia sieberi & 1559 & Compositeae & Dermane & Anti-septic, anti-infective & $\alpha$-Thujone, camphor, $\beta$-thujone \\
\hline
\end{tabular}


Table 2. Antifungal activity (growth inhibition zone, millimeter) of the herbal essential oils and reference antifungal drugs against clinical strains of Malassezia

\begin{tabular}{|c|c|c|c|c|c|}
\hline \multirow[b]{2}{*}{ Fungal strains } & \multicolumn{5}{|c|}{ Antifungals } \\
\hline & $\begin{array}{c}\text { Lavandula stoechas } \\
\text { (Mean } \pm \text { SD) }\end{array}$ & $\begin{array}{c}\text { Cuminum cyminum } \\
\text { (Mean } \pm \text { SD) }\end{array}$ & $\begin{array}{c}\text { Artemisia sieberi } \\
\text { (Mean } \pm \text { SD) }\end{array}$ & $\begin{array}{c}\text { Ketoconazole } \\
\text { (Mean } \pm \text { SD) }\end{array}$ & $\begin{array}{l}\text { Fluconazole } \\
\text { (Mean } \pm \text { SD) }\end{array}$ \\
\hline Malassezia furfur & $46.7 \pm 8.2$ & $50 \pm 0.0$ & $43.3 \pm 14.1$ & $15.6 \pm 5.9$ & $11.6 \pm 3.7$ \\
\hline Malassezia globosa & $50 \pm 0.0$ & $50 \pm 0.0$ & $35 \pm 14.1$ & $15 \pm 7.6$ & $12.4 \pm 2.5$ \\
\hline Malassezia obtusa & $43.7 \pm 12.5$ & $50 \pm 0.0$ & $32.5 \pm 11.9$ & $12.5 \pm 5.0$ & $13.3 \pm 1.5$ \\
\hline
\end{tabular}

In the present study, A. sieberi essential oil indicated lower anti-Malassezia activity than the others. In agreement with our results, Khosravi et al (14) showed that A. sieberi essential oil had inhibitory activity against different Malassezia strains, including M. pachydermatis, M. globosa, $M$. restricta, $M$. sloofiae, $M$. furfur, $M$. nana, $M$. obtuse and M. sympodialis. Previous studies also demonstrated inhibitory activity of $A$. sieberi essential oil against both yeasts (Candida spp., Rhodotorula spp., Cryptococcus spp. and Saccharomyces spp.) and filamentous fungi (Fusarium spp. and Aspergillus spp.) (18,19). In an experimental study conducted by Khosravi et al (20), anti-Malassezia activity of $A$. sieberi essential oil was demonstrated. The results exhibited the improvement rates of $71 \%$ and 91.9\% in clotrimazole and $A$. sieberi essential oil groups after 2 weeks of the treatment $(P<0.05)$. Also, 4 weeks after treatment, the definitive cure rates were achieved approximately $51.6 \%$ for patients receiving clotrimazole and $70.3 \%$ for patients receiving $A$. sieberi essential oil. It is suggested that the major components of $A$. sieberi essential oil, including $\alpha$-and $\beta$-thujone, camphor and 1,8-cineole, can be responsible for inhibiting the growth of saprophytic and pathogenic fungi. The exact mechanisms of antifungal activity are associated with oxidative stress induction, protein alkylation and depolarization disorder of the mitochondrial membrane (21).

Although no report was found concerning the effect of $L$. stoechas essential oil against Malassezia strains but several investigators studied on other fungi. In this context, Zuzarte et al (10) demonstrated the inhibitory effect of L. stoechas against Cryptococcus spp., Candida spp., Aspergillus spp. and dermatophytes. Also, the antifungal activity of $L$. stoechas essential oil from various regions of Algeria was previously evaluated against Candida albicans, Aspergillus niger and A. flavus (22).

In this study, the mean inhibition zones were found to be 14.4 and $12.4 \mathrm{~mm}$ for ketoconazole and fluconazole, respectively. No statistically significant difference was observed between the standard antifungal drugs tested against Malassezia strains. In agreement with our observations, Strippoli et al (23) exhibited that ketoconazole was the most active drug against Malassezia strains. According to Miranda et al (24), these pathogenic yeasts were susceptible to all drugs tested, especially ketoconazole and fluconazole. Fluconazole is an effective antifungal drug for treating Malassezia dermatitis (25). Our results exhibited that fluconazole has lower activity than another azole. This finding is consistent with that of Velegraki et al (26), who showed low activity of fluconazole for Malassezia strains. Prophylactic therapies using fluconazole can be led to frequent recurrence of Malassezia infections. Although the antifungal drugs were found to possess good antifungal activity against Malassezia strains, their effects were lower than the activities shown by the essential oils tested. Previous studies exhibited that combination of various components in each essential oil has higher antifungal activity than each component and studies also suggested that the sum of essential oil components can help in potentiating synergistic effect $(27,28)$.

\section{Conclusion}

In summary, the present study results showed that clinical strains of Malassezia had different susceptibilities to antifungal agents, with $M$. obtusa being the lowest susceptible of the strains. In addition, we demonstrated that the essential oils of L. stoechas, C. cyminum and A. sieberi had inhibitory activities against clinical strains of Malassezia, being C. cyminum essential oil as the most active herbal oil. These results could be used for the design of new antifungal agents with effective clinical importance.

\section{Authors' contributions}

All authors contributed to the study. They conducted the experiment, analyzed and discussed results and prepared the manuscript for publication equally. All read and confirmed its publication.

\section{Conflict of interests}

The authors declare no conflict of interest.

\section{Ethical considerations}

Ethical issues have been observed by the authors.

\section{Funding/Support}

This research has been supported by a research grant from the Amol University of Special Modern Technologies, Amol, Iran (Grant No. D-178).

\section{References}

1. Coutinho SD, Fedullo JD, Correa SH. Isolation of Malassezia spp. from cerumen of wild felids. Med Mycol. 2006;44(4):383-7. doi: 10.1080/13693780500411006.

2. Crespo Erchiga V, Ojeda Martos A, Vera Casano A, Crespo 
Erchiga A, Sanchez Fajardo F. Malassezia globosa as the causative agent of pityriasis versicolor. Br J Dermatol. 2000;143(4):799-803.

3. Pooja A, Arun N, Maninder K. Screening of plant essential oils for antifungal activity against Malassezia furfur. Int J Pharm Pharm Sci. 2013;5(2):37-9.

4. Nazeri $M$, Ata-Bakhshian $R$, Taghizadeh $M$, Talaee $R$, Mahboubi M. Antifungal activity of herbal extracts against Malassezia species. Iran J Dermatol. 2015;18(71):10-5.

5. Faergemann J, Djarv L. Tinea versicolor: treatment and prophylaxis with ketoconazole. Cutis. 1982;30(4):542-5, 50.

6. Avicenna. Al-Qanun fi al Tibb (The Canon of Medicine). Persian Edition by Sharaf-Kandi AR. 1st ed. Tehran: Soroush Press; 1985.

7. Tadjbakhsh H. History of Human and Veterinary Medicine in Iran. Lion: Merial Co; 2003.

8. Angioni A, Barra A, Coroneo V, Dessi S, Cabras P. Chemical composition, seasonal variability, and antifungal activity of Lavandula stoechas L. ssp. stoechas essential oils from stem/ leaves and flowers. J Agric Food Chem. 2006;54(12):436470. doi: 10.1021/jf0603329.

9. Salari S, Khosravi AR, Katiraee F, Ayatollahi Mousavi SA, Shokri H, Nikbakht Borujeni GH. Evaluation of inhibitory effects of Cuminum cyminum oil on the fluconazaole resistant and susceptible Candida albicans isolated from HIV patients in Iran. J Am Sci. 2012;8(5):54-60.

10. Zuzarte M, Gonçalves MJ, Cavaleiro C, Cruz MT, Benzarti A, Marongiu B, et al. Antifungal and anti-inflammatory potential of Lavandula stoechas and Thymus herba-barona essential oils. Ind Crops Prod. 2013;44(Suppl C):97-103. doi: $10.1016 /$ j.indcrop.2012.11.002.

11. Guillot J, Gueho E, Lesourd M, Midgley G, Chevrier G, Dupont B. Identification of Malassezia species. A practical approach. J Med Mycol. 1996;6(2):103-10.

12. Clinical Laboratory Standards Institute. Method for antifungal disk diffusion susceptibility testing in yeasts. Wayne, M44-A: CLSI; 2002

13. Naeini A, Eidi S, Shokri H. Fungitoxicity of Zataria multiflora essential oil against various Malassezia species isolated from cats and dogs with Malassezia dermatitis. Afr J Microbiol Res. 2011;5(9):1057-61.

14. Khosravi AR, Shokri H, Fahimirad S. Efficacy of medicinal essential oils against pathogenic Malassezia sp. isolates. J Mycol Med. 2016;26(1):28-34. doi: 10.1016/j. mycmed.2015.10.012.

15. Naeini AR, Nazeri M, Shokri H. Antifungal activity of Zataria multiflora, Pelargonium graveolens and Cuminum cyminum essential oils towards three species of Malassezia isolated from patients with pityriasis versicolor. J Mycol Med. 2011;21(2):87-91. doi: 10.1016/j.mycmed.2011.01.004.

16. Vijayakumar R, Muthukumar C, Kumar T, Saravanamuthu R. Characterization of Malassezia furfur and its control by using plant extracts. Indian J Dermatol. 2006; 51(2):145-8. doi: 10.4103/0019-5154.26942.
17. Khosravi AR, Minooeianhaghighi MH, Shokri H, Emami SA, Alavi SM, Asili J. The potential inhibitory effect of Cuminum cyminum, Zziphora clinopodioides and Nigella sativa essential oils on the growth of Aspergillus fumigatus and Aspergillus flavus. Braz J Microbiol. 2011;42:216-24.

18. Kalemba D, Kusewicz D, Swiader K. Antimicrobial properties of the essential oil of Artemisia asiatica Nakai. Phytother Res. 2002;16(3):288-91. doi: 10.1002/ptr.856.

19. Kordali S, Kotan R, Mavi A, Cakir A, Ala A, Yildirim A. Determination of the chemical composition and antioxidant activity of the essential oil of Artemisia dracunculus and of the antifungal and antibacterial activities of Turkish Artemisia absinthium, A. dracunculus, Artemisia santonicum, and Artemisia spicigera essential oils. J Agric Food Chem. 2005;53(24):9452-8. doi: 10.1021/jf0516538.

20. Khosravi AR, Shokri H, Darabi MH, Kashani A, Mansouri P, Naser A. Comparative study on the effects of a new antifungal lotion (Artemisia sieberi essential oil) and a clotrimazole lotion in the treatment of pityriasis versicolor. J Mycol Med. 2009;19(1):17-21. doi: 10.1016/j. mycmed.2008.12.001.

21. Olliaro PL, Haynes RK, Meunier B, Yuthavong Y. Possible modes of action of the artemisinin-type compounds. Trends Parasitol. 2001;17(3):122-6.

22. Benabdelkader T, Zitouni A, Guitton Y, Jullien F, Maitre D, Casabianca $\mathrm{H}$, et al. Essential oils from wild populations of Algerian Lavandula stoechas L.: composition, chemical variability, and in vitro biological properties. Chem Biodivers. 2011;8(5):937-53. doi: 10.1002/cbdv.201000301.

23. Strippoli V, Piacentini A, D’Auria FD, Simonetti N. Antifungal activity of ketoconazole and other azoles against Malassezia furfur in vitro and in vivo. Infection. 1997;25(5):303-6.

24. Miranda KC, de Araujo CR, Costa CR, Passos XS, de Fatima Lisboa Fernandes O, do Rosario Rodrigues Silva M. Antifungal activities of azole agents against the Malassezia species. Int J Antimicrob Agents. 2007;29(3):281-4. doi: 10.1016/j.ijantimicag.2006.09.016.

25. Shahid J, Ihsan Z, Khan S. Oral fluconazole in the treatment of pityriasis versicolor. J Dermatolog Treat. 2000;11(2):1013. doi: 10.1080/09546630050517496.

26. Velegraki A, Alexopoulos EC, Kritikou S, Gaitanis G. Use of fatty acid RPMI 1640 media for testing susceptibilities of eight Malassezia species to the new triazole posaconazole and to six established antifungal agents by a modified NCCLS M27-A2 microdilution method and Etest. J Clin Microbiol. 2004;42(8):3589-93. doi: 10.1128/jcm.42.8.35893593.2004

27. Gill AO, Delaquis P, Russo P, Holley RA. Evaluation of antilisterial action of cilantro oil on vacuum packed ham. Int J Food Microbiol. 2002;73(1):83-92.

28. Mourey A, Canillac N. Anti-Listeria monocytogenes activity of essential oils components of conifers. Food Control. 2002;13(4):289-92. doi: 10.1016/S0956-7135(02)00026-9. 